Marquette University

e-Publications@Marquette

College of Nursing Faculty Research and

Publications

Nursing, College of

$8-1-2008$

\title{
Patients' Perceptions of Hospital Discharge Informational Content
}

Lynn Rose Maloney

MarquetteUniversity, lynn.maloney@marquette.edu

Marianne Weiss

Marquette University, marianne.weiss@marquette.edu

Accepted version. Clinical Nursing Research, Vol. 17, No. 3 (August 2008): 200-219. DOI. (C) 2008 SAGE Publications. Used with permission. 


\title{
Patients' Perceptions of Hospital Discharge Informational Content
}

\author{
Authors: Lynn R. Maloney \& Marianne E. Weiss; Marquette University College of
} Nursing, Milwaukee, Wisconsin

\begin{abstract}
Ensuring that patients' informational needs have been met prior to hospital discharge sets the stage for successful self-management of recovery at home. This secondary analysis study aims to identify differences in the amount of discharge teaching content needed and received by adult medical-surgical patients on the basis of their sociodemographic characteristics and hospitalization-related factors. The Quality of Discharge Teaching Scale (QDTS) is used to measure patients' perceptions of the amount of discharge-related informational content they needed and received. Eighty-nine percent of patients receive more informational content than they perceived they needed. Nonwhite patients report more content needed than White patients. Patients with prior hospitalizations and cardiac patients report greater amounts of content received. The QDTS content subscales provide a mechanism for assessing patient perceptions of discharge informational needs and discharge content received that can be used for clinical practice and quality monitoring.
\end{abstract}

The effectiveness of discharge preparation has become increasingly important to patient outcomes and satisfaction with hospital care and services. Patients are being discharged in an intermediate phase of recovery (Korttila, 1991), with the recovery process expected to extend into the home setting. Within a healthcare environment faced with nursing workforce shortages, short length of hospital stay, and increased acuity at the time of discharge, there is less time available than in the past to educate patients about posthospital care and to coordinate postdischarge services (Johansson, Hupli, \& Salantera, 2002; McMurray, Johnson, Wallis, Patterson, \& Griffiths, 2007; Titler \& Pettit, 1995). Patients discharged with unmet needs are at higher risk for posthospital complications, readmission, and decreased satisfaction with care (Mamon et al., 1992; McMurray et al., 2007; Walker, Hogstel, \& Curry, 2007). Until recently, measures to assess adequacy of discharge teaching and readiness for hospital discharge have not been widely available for research or clinical practice (Weiss et al., 2007; Weiss \& Piacentine, 2006). Yet assessment of discharge preparation is critical for early identification of patients' unmet learning needs and intervention to enhance discharge readiness.

The focus of this study was a comparison of the amount of discharge informational 
content needed and received by adult medical-surgical patients prior to hospital discharge. The essential questions were (a) How much content do adult medical-surgical patients perceive they need and receive in preparation for discharge? and (b) Are there systematic differences in the amount of discharge informational content needed and received based on specific patient characteristics and hospitalization factors? For the purposes of this study, discharge content needed refers to patients' perceptions of the amount of information needed in preparation for discharge. "Content received" refers to patients' perceptions of the amount of information received in preparation for discharge, an indirect measure of the nursing process of discharge teaching.

\section{Problem}

\section{Review of Related Literature}

Discharge planning is an essential process in the patient's hospital experience during which needs are identified and evaluated, and assistance is provided in anticipation of leaving the facility (Jackson, 1994; McMurray et al., 2007; Walker et al., 2007). Planned preparation promotes timely discharge, anticipation of postdischarge needs and potential problems, continuity of care between hospital and home or community services (Jackson, 1994; Walker et al., 2007), and reduced rate of postdischarge complications and readmission (Mamon et al., 1992; Mistiaen, Francke, \& Poot, 2007). To perform discharge preparation well, providers must accurately evaluate patients' needs for assistance early in the recovery period (Kleinpell, 2004; Reiley et al., 1996). Knowing what needs patients identify as being important prior to discharge promotes discharge readiness (Anthony \& Hudson-Barr, 2004).

Discharge teaching is a critical component of discharge preparation to facilitate transition from hospital to home (McNamee \& Wallis, 1999; Smith \& Liles, 2007). Appropriate and useful discharge preparatory information facilitates informed health decision making after hospital discharge (McMurray et al., 2007). Nurse-delivered discharge education increases self-care adherence, improves clinical outcomes, and reduces cost of care (Koelling, Johnson, Cody, \& Aaronson, 2005). Nurses integrate patient teaching and other components of discharge planning into the delivery of care throughout the hospital stay. The outcome of these efforts is discharge readiness (Foust, 2007; Weiss et al., 2007).

Numerous studies and clinical reports provide evidence that patient and families encounter a variety of problems after discharge, such as difficulties with functional abilities and in carrying out personal care (Mamon et al., 1992; Schaefer, Anderson, \& Simms, 1990; Tierney,

\section{Maloney \& Weiss}


Closs, Hunter, \& Macmillan, 1993), delays in provision of community services (Grimmer, Moss, \& Falco, 2004; Simon, Showers, Blumenfield, Holden, \& Wu, 1995), and unmet emotional needs (LeClerc, Wells, Craig, \& Wilson, 2002; Wade, Pletsch, Morgan, \& Menting, 2000). These problems are often attributed to having unmet informational needs (Grimmer et al., 2004; Henderson \& Zernike, 2001; Jacobs, 2000; Reiley et al., 1996; Wade et al., 2000). Patients who do not feel that they receive adequate information express dissatisfaction with their discharge instruction and postdischarge experiences (Bull, 1994b; Clark et al., 2005).

Several reasons have been cited to explain why patients and their families do not receive or assimilate the information they feel they need and are left with feelings of being unprepared. In some cases, patients may be reluctant to ask questions because of perceived lack of professionals' time, an unfamiliar environment, lack of continuity in staff, and a feeling they may have already been told (Henderson \& Zernike, 2001). In other situations, patients, family members, and health care providers may have different perceptions about information that is important (Suhonen, Nenonen, Laukka, \& Valimake, 2005) and about readiness for hospital discharge (Congdon, 1994). Patients may have different expectations about their own ability to perform self-care activities (Bull, 1994a) and cope with change (Clark, Steinberg, \& Bischoff, 1997). Discrepancies in perceptions of the plan of care may become evident in later difficulties in managing care at home (Bull, Hansen, \& Gross, 2000).

Patients should be central within the discharge preparation process (Congdon, 1994; Procter, Wilcockson, Pearson, \& Allgar, 2001) and actively involved (Anthony \& Hudson-Barr, 2004; Cleary, Horsfall, \& Hunt, 2003), but inadequate participation is frequently reported (Bull \& Roberts, 2001; Congdon, 1994; Grimmer et al., 2004; LeClerc et al., 2002). In a study by Tierney et al. (1993), only $41 \%$ of patients were asked how they would manage after discharge. Patients who are involved and participatory in decisions regarding their care are more likely to be satisfied with overall outcomes (Bull et al., 2000).

Informational needs may be different based on certain patient characteristics. Nonwhite patients have rated teaching about medications and health promotion as very important (Oermann, Harris, \& Dammeyer, 2001) but have also reported receiving less interactive informational support than White patients (Maly, Leake, \& Silliman, 2003) and less involvement in medical treatment decision making (Cooper-Patrick et al., 1999). Cultural differences may affect communication and understanding, especially when language barriers are present (Maly et al., 2003).

Other demographic differences in discharge informational needs have been reported.

\section{Maloney \& Weiss}


Female patients view the need for information about illness and treatment of greater importance than males (Oermann et al., 2001). In addition, females tend to ask more questions, generally receive more information, and have more partnership building with their health care providers than male patients (Suhonen et al., 2005). Younger patients place more importance on health information compared with older adults (Oermann et al., 2001; Suhonen et al., 2005). Older adults give greater importance to having access to persons, resources, or services to assist them with activities when they are unable due to illness-induced limitations (Bull, 1994b). Patients with limited education place greater importance on nurse teaching about illness, treatments, and health promotion (Oermann et al., 2001). Highly educated patients reported they desired health information but received less than desired (Van Veenendaal, Grinspun, \& Adriaanse, 1996).

Patients' perceptions of receiving adequate or inadequate information prior to discharge do not necessarily reflect the actual amount or type of teaching provided by their nurses. Several explanations have been offered to explain the discrepancy: lack of attention during the information exchange (e.g., due to issues of pain or lack of sleep; Galloway, Rebeyka, Saxe-Braithwaite, Bubela, \& McKibbon, 1997), difficulty coping (e.g., feeling anxious, stressed or in denial of impending discharge; McNamee \& Wallis, 1999), feelings of intimidation (Paterson, Kieloch, \& Gmiterek, 2001), or feelings of information overload and being more selective in what information they wanted to receive (Burkhead, Jones, VonCannon, \& Hu, 2003; Jacobs, 2000).

Characteristics of the nurses delivering the teaching may affect the communication exchange and quality of information provided. Professionals often use complex terminology that patients do not understand (Henderson \& Zernike, 2001) or may give inconsistent and contradictory information (Bull, 1994b; Paterson et al., 2001). Professionals may vary the informational content given to patients based on preconceived ideas and beliefs (Mordiffi, Tan, \& Wong, 2003) or may convey negative attitudes (Bull \& Kane, 1996). Nurses with more experience and more exposure to specific populations convey a broader perspective on factors to consider for discharge preparation (Bull, 1994b; Tilus, 2002).

Health care professionals often expect that patients will assume responsibility for their health by asking questions to solicit needed information (Bull, 1994b). On the other hand, patients expect health care professionals to provide the necessary information as a routine aspect of the care encounter. Nurses may see themselves as experts and provide the information they think will be important to patients rather than assessing for information patients

\section{Maloney \& Weiss}


perceive to be important (Mordiffi et al., 2003). Communication difficulties and lack of understanding can result in a mismatch in patients' and health professionals' expectations, which can widen the informational gap (Mordiffi et al., 2003). Both patients and health professionals identify effective communication as critical for discharge preparation and lack of communication a factor that results in poor outcomes (Bull, 1994b; Bull \& Kane, 1996).

With the goal of discharge preparation being successful transition home, patients need to be involved in identifying the information they perceive to be important and to determine whether their needs have been met prior to discharge. Awareness of patients' perceptions of discharge informational needs, and patient characteristics and hospitalization factors that may shape these perceptions, will promote better discharge preparation and patients' perceptions of readiness for discharge.

\section{Theoretical Framework}

Meleis' middle range theory of transitions (Meleis, Sawyer, Im, Hilfinger Messias, \& Schumacher, 2000) provided a useful framework for conceptualizing the patients' experience during the hospital discharge process. Changes in health and illness create a process of transition and a period of potential vulnerability, exposing an individual to potential risks such as a problematic or extended recovery or delayed or unhealthy coping. Cultural beliefs and attitudes, socioeconomic status, and preparation are personal and environmental transition conditions that can facilitate or inhibit progress. Nursing therapeutics are nurse actions focused on the promotion of healthy patterns of response during the transition experience. Education targeting assumption of new role responsibilities and implementation of new role skills is a key nursing strategy to promote successful transitions (Meleis et al., 2000; Meleis \& Trangenstein, 1994).

For this study, the transitional process was viewed as the process of preparing for and transitioning from hospital to home-based care and recovery. Transition conditions were patients' sociodemographic characteristics (age, gender, race/ethnicity, education, living arrangement) and hospitalization factors (prior hospitalizations, planned or unplanned admission, type of admission, length of stay) that may influence discharge information needs. Nursing therapeutics was represented in this study by the amount of content received by the patient during discharge teaching in preparation for discharge. Patient perception of content received was viewed as the receiver characteristic of the nursing process of discharge teaching, a communication process with message sender and receiver components. Patterns of response during the discharge transition, readiness for discharge and postdischarge outcomes, were

\section{Maloney \& Weiss}


measured in the larger study from which this study's data were derived (Weiss et al., 2007).

\section{Purpose of the Study}

The purpose of this study was to identify whether there are differences in the amount of discharge informational content needed and received by adult medical-surgical patients based on selected patient characteristics and hospitalization factors. The following hypotheses were tested:

1. Adult medical-surgical patients will perceive that they receive more discharge informational content than their perceived need.

2. The amount of discharge teaching content needed will differ across patients grouped on the basis of their sociodemographic characteristics and factors related to their hospitalization. For example, older patients or those with an unplanned hospitalization may have greater needs for discharge informational content.

3. The amount of discharge teaching content received by patients will differ across patients grouped on the basis of their sociodemographic characteristics and factors related to their hospitalization. For example, older patients or those with an unplanned hospitalization may receive greater amounts of discharge teaching content.

\section{Design}

The study used a cross-sectional descriptive and comparative secondary analysis design to analyze selected data collected during a larger study of predictors and outcomes of hospital discharge readiness. The larger study was conducted with a sample of adult medical-surgical patients, postpartum women, and parents of hospitalized children all of whom were discharged from acute care facilities (Weiss \& Piacentine, 2006; Weiss et al., 2007; Weiss et al., in press). The study reported here includes variables specific to the amount of discharge information needed and received by adult medical-surgical patients during the discharge preparatory process and patient characteristics and factors that may influence perceptions of informational needs and the amount of discharge-related teaching received. The disease-specific content of discharge teaching was not collected or evaluated in the primary study and therefore was not available for this secondary analysis. The focus of both the original study and this secondary analysis was to illuminate relationships between variables that could

\section{Maloney \& Weiss}


be captured across multiple patient populations. The amount of teaching needed and received are variables relevant to planning for patient services at individual and aggregate patient levels.

\section{Sample and Setting}

The sample consisted of 115 patients derived from the original study sample in which 147 adult medical-surgical patients were enrolled and 135 completed a questionnaire at the time of discharge (Weiss et al., 2007). Twenty of the 135 patients who completed the discharge survey were excluded due to missing data on the dependent variables for this analysis (amount of discharge teaching content needed and received). Using Cohen's power table, a sample size of 64 was recommended for a two-group analysis of variance (ANOVA), $a_{c}=.05$, Power $=.80$, with a medium (.30) effect (Cohen, 1992). Patients in the original study were recruited from general medical, surgical, and cardiac inpatient units of an urban tertiary-level medical center in the Midwestern United States and met the following inclusion criteria: at least 18 years of age, home discharge planned, ability to read and speak English, and telephone access for follow-up contacts. Hospice patients were excluded.

\section{Method}

\section{Variables and Instruments}

Patient characteristics

Patient characteristics of age, gender, race/ethnicity, living arrangement (living alone or with another), and education were collected on a study enrollment questionnaire completed by the patient. Hospitalization factors including prior hospitalization (yes or no), planned or unplanned admission, admission type (medical or surgical), length of hospital stay, and presence or absence of major medical conditions (diabetes, pulmonary, cardiac) were obtained by patient report and medical record review.

\section{Quality of Discharge Teaching Scale}

Educational preparation for discharge was measured using the content needed and content received subscales of the Quality of Discharge Teaching Scale (QDTS; Weiss et al., 2007). Discharge teaching was conceptualized as the composite of all teaching received by the patient (from the patient's perspective) during hospitalization in preparation for discharge and the postdischarge period at home. The QDTS consists of a total of 24 items in two major subscales: content and delivery. The "content" subscale was used for the dependent variable in the analyses presented in this paper. The "delivery of teaching" subscale of the QDTS addressed the skill of the nurses in delivering the content and results have been reported

\section{Maloney \& Weiss}


elsewhere (Weiss et al., 2007).

The content subscale consists of six paired items (a total of 12 items) using a parallel format to request information about the amount of informational content needed and received in preparation for discharge. Two sets of scores are generated from the content subscale-amount of content needed (six items) and amount of content received (six items). The six paired items ask the respondent to rate the amount of discharge informational content needed and received in the following domains: (a) information about taking care of oneself, (b) emotions to expect after discharge, (c) information about medical needs and/or treatments, (d) practice with treatments and/or medications, (e) information about who and when to call for problems or emergencies, and (f) family members' informational needs. The QDTS uses an 11-point self-rating scale with anchor words (e.g., none, a great deal) located at the 0 and 10 poles to cue the participant to the meaning of the numeric scale. Higher scores indicate greater amount of discharge teaching content needed and received. Validity of the scale was established with the larger study sample. The Cronbach's alpha reliability coefficients for the total scale and subscales all exceeded .80 (Weiss et al., 2007).

\section{Procedures}

University and hospital institutional review board approvals were obtained. For the original study, the principal investigator (M.W.) trained undergraduate and graduate nursing students, who served as research assistants (RAs), in the study procedures for obtaining informed consent and data collection methods. Study enrollment took place during the hospitalization prior to the day of discharge. Patient characteristics were collected at that time using the study enrollment form. A mechanism was established with study units for unit nurses to distribute a discharge questionnaire containing the QDTS within 4 hours prior to discharge. Patients completed the form and returned it in a sealed envelope to a data collection box located at the nursing unit. The study RAs reviewed the medical records to capture hospitalization data.

\section{Data Analysis}

SPSS 14.0 graduate pack was used for the secondary analyses (Norusis, 2006). Before conducting the analyses, we examined each quantitative variable for accuracy of data entry, missing values, and fit between their distributions and the assumptions of the selected analyses. Data were examined using box plots and stem-and-leaf and there were no outliers. Pairwise linearity was checked using within-group scatterplots and found to be satisfactory.

\section{Maloney \& Weiss}


Race/ethnicity was recoded into a dichotomous variable, White and Nonwhite, due to limited numbers of Hispanic and Asian participants. Education was reduced from 7 to 4 categories because of inadequate numbers of participants with less than high school education. Length of stay was reduced from total days in hospital to three categories with approximately equal numbers of participants to create a variable that could be used as an independent variable in the analyses.

Descriptive statistics were calculated for patient characteristics and hospitalization factors. Paired-samples $t$ tests were conducted to determine differences between QDTS content needed and received scores to address Hypothesis 1. For Hypothesis 2, patient characteristics and hospitalization factors were entered as the independent variables and QDTS content needed subscale scores as the dependent variable in separate one-way between-subjects ANOVA tests for differences in content needed by age, education, and length of stay. Independent-samples $t$ tests were conducted to determine differences in content needed by gender, race/ethnicity, living arrangement, prior admission, planned admission, medical or surgical admission, and medical diagnoses (cardiac, pulmonary, and diabetes). The same procedures were carried out to address Hypothesis 3 using the QDTS content received subscale score as the dependent variable.

\section{Findings}

Patient characteristics and hospitalization factors for the sample are presented in Table 1. The 115 participants included 64 (55.7\%) women and 51 (44.3\%) men. The sample ranged in age from 20 to 88 with a mean of $52.8(S D=15.3)$. Fifty-two percent of the sample was married, with $18 \%$ reporting that they lived alone. The sample was predominately White (64\%). The race/ethnicity distribution of the sample reasonably approximated the demographics for the geographic location (city) of the study site (50\% White, 37\% Black, 12\% Hispanic, and less than 3\% Asian; U.S. Census Bureau, 2000), except that Hispanic participants were not recruited in numbers proportional to the local demographics due to restriction of the study sample to English speaking. The patient sample was fairly well educated, with $58.4 \%$ having at least a partial college or higher educational degree. Ninety-two percent of the sample had been previously hospitalized and 49\% were aware of the impending admission for more than $24 \mathrm{hr}$ (planned admission). Fifty-four percent of the sample was admitted for medical reasons and the remainder for surgical intervention. Major medical diagnoses were present in the sample: 52\% with a cardiac diagnosis, $24 \%$ with a pulmonary diagnosis, and $18 \%$ with diabetes. The average

\section{Maloney \& Weiss}


length of stay was 4.5 days, which is comparable to the national average of 4.8 days (DeFrances \& Hall, 2007).

The paired-samples $t$ test comparing the QDTS content needed and received subscales indicated a statistically significant difference, $t(114)=7.56 ; p<.001$. The amount of informational content needed by patients was substantially less $(M=26.2 ; S D=15.6)$ than the amount of information they received $(M=37.5$; $S D=15.5)$. Of the small number of patients receiving less information than their stated need $(n=11)$, the majority were male $(55 \%)$, White (64\%), less than 45 years of age (55\%), had a high school or higher educational degree (81\%), and were living alone (82\%).

No significant differences in discharge content needed were found in the ANOVA tests using the patient characteristics of age and education and the hospitalization factor of length of stay as the independent variables. Likewise, no significant differences in content needed were found when independent samples $t$ tests were conducted for the independent variables of gender and living status (patient characteristics) as well as prior hospitalization, planned admission, type of admission, or medical diagnosis (hospitalization factors). The only significant finding in analyses of content needed was that Nonwhite patients $(M=32.1 ; S D=14.9)$ reported needing more information than White patients $(M=22.9 ; S D=15.4), t(111)=3.1 ; p$ $=.002($ Table 2$)$.

Using the same tests to evaluate the differences in discharge content received by patient characteristics and hospitalization factors, significant differences were detected for tests comparing patients with or without prior hospitalization- $t(112)=2.2 ; p=.04$-and for patients with or without a cardiac diagnosis- $t(113)=-2.4 ; p=.02$. Patients with a prior hospital admission reported that they received more discharge content $(M=37.9 ; S D=16.0)$ than those experiencing their first admission $(M=32.0 ; S D=6.6)$. Patients with a cardiac diagnosis received more discharge content $(M=40.9$; $S D=15.7)$ than those without a cardiac diagnosis $(M=33.91 ; S D=14.7)($ Table 2).

\section{Discussion}

Most patients in this study received more teaching than they felt they needed. One interpretation of this finding is that the nurses were skilled at assessment of need and targeted the discharge teaching to ensure that the individual needs of patients were met or exceeded. Another interpretation could be that patients underassess their real need level, and nurses recognize the actual amount of teaching needed to prepare patients for caring for their own

\section{Maloney \& Weiss}


needs at home. In this study sample, scores for perceived content needed were relatively low (mean of 26 in a possible score of 60 ) and below the midpoint on the scale's scoring of none to a great deal. Received scores were higher than the midpoint. Patients with previous hospitalizations received more informational content, perhaps reflecting the nurses' awareness of readmission risk and emphasis on education as anticipatory risk reduction for patients who had experienced multiple hospitalizations.

A third interpretation could be that the use of standardized discharge planning protocols, including standardized discharge teaching plans with predefined content, ensures comprehensive discharge preparation (Mistiaen et al., 2007; Walker et al., 2007). These standard discharge teaching plans are often disease-condition-specific. In the study sample, there were no differences in the amount of teaching received according to sociodemographic characteristics of the patients. However, the greater amount of content received by cardiac patients as a group may reflect the scope of cardiac discharge teaching plans that emphasize information required for self-care after discharge and readmission prevention. Among the small number of patients $(n=11)$ who received less informational content than they felt they needed, the majority $(n=9)$ were living alone and may have felt the need for more vigilance regarding their own health care issues. This is congruent with findings in the literature which indicate that patients responsible for their own health care report that they need more information about prevention and management of potential complications (Jacobs, 2000).

A dilemma in using patient perception of discharge content needed as a benchmark against which to assess amount of teaching that should be provided is the accuracy of the patient's perception related to their needs for the forthcoming postdischarge period, which they have yet to experience. Nurses have perceptions of patient need for informational preparation that are based on their knowledge of the recovery trajectory and their assessment of each individual patient. Receiving more education than needed reflects a lack of congruence between patient perception of need and nurses' view of what should be provided. Nurses may base their discharge teaching on information they perceive as important, not on aspects that are considered important by patients. Prior research has noted discrepancies between patient and provider views of informational importance (Mordiffi, Tan, \& Wong, 2003; Suhonen et al., 2005). There is no research evidence related to comparisons of nurses and patients' perceptions of discharge informational needs and their relationship to postdischarge outcomes.

Reliance on clinical protocols and a lack of individualization may result in discrepancies in meeting patients' discharge preparation needs (McMurray et al., 2007). Patients differ in the

\section{Maloney \& Weiss}


kind and amount of information they seek, which can vary during different stages of recovery (Smith \& Liles, 2007). Clark et al. (2005) found that patients perceive a difference between general patient education and informational needs in preparation for discharge. Patients' conceptualization of discharge teaching as the just-in-time teaching provided immediately before leaving the hospital may explain Clark et al.'s thesis that meeting educational preparation needs throughout hospitalization may not necessarily result in satisfaction with discharge teaching at the time of discharge.

Race/ethnicity was the sole characteristic on which there was a difference in content needed, with Nonwhite patients reporting a greater amount of discharge teaching needed than White patients. There were no differences in the amount of content received by race/ethnicity group. Others have found that Nonwhite patients are provided with less information about their disease and treatment (Cooper-Patrick et al., 1999; Oermann et al., 2001) and as a result may be less actively involved in medical decision making regarding their health (Maly et al., 2003). Although these studies were unable to identify specific underlying causes for these disparities, ethnic differences between patients and providers can pose a barrier to partnership and effective communication (Cooper-Patrick et al., 1999; Maly et al., 2003). It is unclear whether this study's findings are a result of cultural differences or other factors such as differences in informational expectations, communication barriers, or lack of knowledge regarding cultural beliefs and values of the importance of health education.

Prior hospitalization and cardiac diagnosis were two characteristics on which there were differences in content received. Those having a prior hospitalization and those with a cardiac condition reported receiving a greater amount of discharge information than those experiencing a first admission or those with diagnoses other than cardiac. A prior admission conveys a sense of unsuccessful discharge planning, thereby prompting nurses to intensify instructional efforts (Hansen Bull, \& Gross, 1998; Walker et al., 2007). Patients experiencing a first acute event may be at a point of uncertainty and struggling to cope at the time of hospital discharge rather than in a phase of information seeking and decision making about posthospital care (Decker et al., 2007; Jensen \& Petersson, 2003), which may preclude extensive or even optimal discharge teaching. For cardiac patients, emphasis on discharge preparation as intervention to prevent readmission may explain the findings in this subset of patients. Recognition of the importance of self-vigilance and management in the postdischarge period may be heightened in patients who have previously experienced hospitalization or who have a cardiac diagnosis. Greater attention may be paid to the teaching provided for discharge preparation. The reasons for differences in

\section{Maloney \& Weiss}


perception of the amount of discharge teaching were not the subject of this study and should be explored in future research.

The limitations of this study include the summative format of the QDTS tool, which addressed general and not disease-specific content areas of discharge teaching, patient report as a measure of the amount of teaching received prior to discharge, which may have been affected by recall of teaching over the course of hospitalization, and the use of a preexisting data set compiled from one hospital setting, which limits generalizability. It is recommended that this study be replicated within different hospital settings and additional variables explored relevant to the discharge teaching process.

\section{Application}

The QDTS content needed and received subscales provide a mechanism for patient assessment and quality monitoring that could be incorporated into clinical practice environments. Combined with tools to measure disease-specific knowledge acquisition by the patient prior to discharge, patient discharge informational needs could be assessed for patients with specific conditions and across patient populations. Delivery of discharge teaching content can then be targeted and evaluated from the patient's perspective.

The content needed subscale can be used as an assessment tool to assist in early identification of the amount of learning perceived to be needed by the patient. Comparing needed and received scores provides a measure of achievement of teaching goals at the individual patient level. In cases where informational needs are not met, supplemental teaching can be implemented prior to discharge to reduce learning deficiencies and enhance discharge readiness.

Using a patient-report measure of discharge teaching received can be viewed as both a patient-centered outcome measure and an indirect measure of the nursing process activity of discharge teaching. Internal hospital benchmarks could be developed and monitored and improvements targeted. On an organizational level, the QDTS may support efforts to systematically and longitudinally monitor and manage the quality of discharge teaching.

Ensuring that patients' informational needs have been met prior to discharge sets the stage for successful management of care and recovery at home. The findings of the original study, from which this study sample was taken, validate the importance of discharge readiness in reducing postdischarge coping difficulty, and avoiding unplanned utilization of health services, including readmission (Weiss et al., 2007).

\section{Maloney \& Weiss}




\section{Note}

- Please address correspondence to Lynn R. Maloney, Marquette University College of Nursing, PO Box 1881, Milwaukee, WI 53201; e-mail: Lynn.maloney@marquette.edu.

- Lynn R. Maloney, RN, MSN, ANP-BC, PhD Candidate, is an adult nurse practitioner for Independent Psychiatric Consultants, Inc. Her clinical background is adult and geriatric medical-surgical nursing. Her research area of interest is the management of chronic illness and its relevance to nursing practice.

- Marianne E. Weiss, DNSc, RN, is an associate professor and Wheaton Franciscan Healthcare-Sister Rosalie Klein Professor of Women's Health at Marquette University College of Nursing. Her program of research focuses on the impact of hospital nursing care on discharge and post-discharge outcomes.

\section{References}

Anthony, M. K., \& Hudson-Barr, D. C. (2004). A patient-centered model of care for hospital discharge. Clinical Nursing Research, 13(2), 117-136.

Bull, M. J. (1994a). Elders' and family members' perspectives in planning for hospital discharge. Applied Nursing Research, 7(4), 190-192.

Bull, M. J. (1994b). Patients' and professionals' perceptions of quality in discharge planning. Journal of Nursing Care Quality, 8(2), 47-61.

Bull, M. J., Hansen, H. E., \& Gross, C. R. (2000). Predictors of elder and family caregiver satisfaction with discharge planning. The Journal of Cardiovascular Nursing, 14(3), 76-87.

Bull, M. J., \& Kane, R. L. (1996). Gaps in discharge planning. The Journal of Applied Gerontology, 15(4), 486-500.

Bull, M. J., \& Roberts, J. (2001). Components of a proper hospital discharge for elders. Journal of Advanced Nursing, 35(4), 571-581.

Burkhead, V., Jones, E. D., VonCannon, L., \& Hu, J. (2003). ENTER: A care guide for successfully educating patients. Journal for Nurses in Staff Development, 19(3), 143-146.

Clark, M., Steinberg, M., \& Bischoff, N. (1997). Patient readiness for return to home: Discord between expectations and reality. Australian Occupational Therapy Journal, 44, $132-141$.

14 Maloney \& Weiss 
Clark, P. A., Drain, M., Gesell, S. B., Mylod, D. M., Kaldenberg, D. O., \& Hamilton, J. (2005). Patient perceptions of quality in discharge instruction. Patient Education and Counseling, 59, 56-68.

Cleary, M., Horsfall, J., \& Hunt, G. E. (2003). Consumer feedback on nursing care and discharge planning. Journal of Advanced Nursing, 42(3), 269-277.

Cohen, J. (1992). A power primer. Psychological Bulletin, 112(1), 155-159.

Congdon, J. G. (1994). Managing the incongruities: The hospital discharge experience for elderly patients, their families, and nurses. Applied Nursing Research, 7(3), 125-131.

Cooper-Patrick, L., Gallo, J. J., Gonzales, J.J., Vu, H. T., Powe, N. R., Nelson, C., et al. (1999). Race, gender, and partnership in the patient-physician relationship. Journal of American Medical Association, 282(6), 583-589.

Decker, C., Garavalia, L., Chen, C., Buchanan, D. M., Nugent, K., Shipman, A., et al. (2007). Acute myocardial infarction patients' information needs over the course of treatment and recovery. Journal of Cardiovascular Nursing, 22(6), 459-465.

DeFrances, C. J., \& Hall, M. J. (2007). 2005 National hospital discharge survey. In Advance Data From Vital and Health Statistics (CDC Publication No. 385, pp. 1-20). Washington, DC: U.S. Department of Health and Human Services.

Foust, J. B. (2007). Discharge planning as part of daily nursing practice. Applied Nursing Research, 20, 72-77.

Galloway, S., Rebeyka, D., Saxe-Braithwaite, M., Bubela, N., \& McKibbon, A. (1997). Discharge information needs and symptom distress after abdominal aortic surgery. Canadian Journal of Cardiovascular Nursing, 8(3), 9-15.

Grimmer, K., Moss, J., \& Falco, J. (2004). Experiences of elderly patients regarding independent community living after discharge from hospital: A longitudinal study. International Journal for Quality in Health Care, 16(6), 465-472.

Hansen, H. E., Bull, M., \& Gross, C. R. (1998). Interdisciplinary collaboration and discharge planning communication for elders. Journal of Nursing Administration, 28(9), 37-46.

Henderson, A., \& Zernike, W. (2001). A study of the impact of discharge information for surgical patients. Journal of Advanced Nursing, 35(3), 435-441.

Jackson, M. F. (1994). Discharge planning: Issues and challenges for gerontological nursing. A critique of the literature. Journal of Advanced Nursing, 19, 492-502.

Jacobs, V. (2000). Informational needs of surgical patients following discharge. Applied Nursing Research, 13(1), 12-18.

\section{Maloney \& Weiss}


Jensen, B. O., \& Petersson, K. (2003). The illness experiences of patients after a first time myocardial infarction. Patient Education and Counseling, 51, 123-131.

Johansson, K., Hupli, M., \& Salantera, S. (2002). Patients' learning needs after hip arthroplasty. Journal of Clinical Nursing, 11, 634-639.

Kleinpell, R. M. (2004). Randomized trial of an intensive care unit-based early discharge planning intervention for critically-ill elderly patients. American Journal of Critical Care, 13(4), 335-345.

Koelling, T. M., Johnson, M. L., Cody, R. J., \& Aaronson, K. D. (2005). Discharge education improves clinical outcomes in patients with chronic heart failure. Circulation, 111, 179-185. Retrieved August 20, 2006, from http://www.circulationaha.org

Korttila, K. (1991). Anaesthesia for ambulatory surgery: Firm definitions of "Home Readiness" needed. Annals of Medicine, 23(6), 635-636.

LeClerc, C. M., Wells, D., Craig, D., \& Wilson, J. L. (2002). Falling short of the mark: Tales of life after hospital discharge. Clinical Nursing Research, 11(3), 242-263.

Maly, R. C., Leake, B., \& Silliman, R. A. (2003). Health care disparities in older patients with breast carcinoma. Cancer, 97(6), 1517-1527.

Mamon, J., Steinwachs, D. M., Fahey, M., Bone, L. R., Oktay, J., \& Klein, L. (1992). Impact of hospital discharge planning on meeting planning needs after returning home. Health Services Research, 27(2), 155-175.

McMurray, A., Johnson, P., Wallis, M., Patterson, E., \& Griffiths, S. (2007). General surgical patients' perspectives of the adequacy and appropriateness of discharge planning to facilitate health decision-making at home. Journal of Clinical Nursing, 16, 1602-1609.

McNamee, S., \& Wallis, M. (1999). Patient problems and evaluation of patient discharge education after coronary artery bypass graft surgery. Contemporary Nurse, 8(3), 107-115.

Meleis, A. I., \& Trangenstein, P. A. (1994). Facilitating transitions: Redefinition of the nursing mission. Nursing Outlook, 42(6), 255-259.

Meleis, A. I., Sawyer, L. M., Im, E.-O., Hilfinger Messias, D. K., \& Schumacher, K. (2000). Experiencing transitions: An emerging middle-range theory. Advances in Nursing Science, 23(1), 12-28.

Mistiaen, P., Francke, A. L., \& Poot, E. (2007). Interventions aimed at reducing problems in adult patients discharged from hospital to home: a systematic meta-review. BMC Health Services Research, 7, 47. Retrieved February 5, 2008, from http://biomedcentral.com/

\section{Maloney \& Weiss}


1472-6963/7/47

Mordiffi, S. Z., Tan, S. P., \& Wong, M. (2003). Information provided to surgical patients versus information needed. Association of Operating Room Nurses Journal, 77(3), 546-562.

Norusis, M. J. (2006). SPSS 14.0 guide to data analysis. Upper Saddle River, NJ: Prentice Hall.

Oermann, M. H., Harris, C. H., \& Dammeyer, J. A. (2001). Teaching by the nurse: How important is it to patients? Applied nursing Research, 14(1), 11-17.

Paterson, B., Kieloch, B., \& Gmiterek, J. (2001). "They never told us anything": Post discharge instruction for families of persons with brain injuries. Rehabilitation Nursing, 26(2), 48-53.

Procter, S., Wilcockson, J., Pearson, P., \& Allgar, V. (2001). Going home from hospital: The carer/patient dyad. Journal of Advanced Nursing, 35(2), 206-217.

Reiley, P., lezzoni, L. I., Phillips, R., Davis, R. B., Tuchin, L. I., \& Calkins, D. (1996). Discharge planning: Comparison of patients' and nurses' perceptions of patients following hospital discharge. IMAGE: Journal of Nursing Scholarship, 28(2), 143-147.

Schaefer, A. L., Anderson, J. E., \& Simms, L. M. (1990). Are they ready? Discharge planning for older surgical patients. Journal of Gerontological Nursing, 16(10), 16-19.

Simon, E. P., Showers, N., Blumenfield, S., Holden, G., \& Wu, X. (1995). Delivery of home care services after discharge: What really happens. Health \& Social Work, 20(1), 5-14.

Smith, J., \& Liles, C. (2007). Information needs before hospital discharge of myocardial infarction patients: A comparative, descriptive study. Journal of Clinical Nursing, 16, 662-671.

Suhonen, R., Nenonen, H., Laukka, A., \& Valimaki, M. (2005). Patients' informational needs and information received do not correspond in hospital. Journal of Clinical Nursing, 14, 1167-1176.

Tierney, A. J., Closs, S. J., Hunter, H. C., \& MacMillan, M. S. (1993). Experiences of elderly patients concerning discharge from hospital. Journal of Clinical Nursing, 2, 179-185.

Tilus, S. (2002). The influence of nursing education on collaborative discharge planning. Journal of Nursing Staff Development, 18(5), 274-281.

Titler, M. G., \& Pettit, D. M. (1995). Discharge readiness assessment. Journal of Cardiovascular Nursing, 9(4), 64-74.

U.S. Census Bureau. (2000). State and county quickfacts: U.S. Census Bureau. Retrieved March 28, 2007, from http://quickfacts.census.gov/qfd/states/55/55079.html

Van Veenendaal, H., Grinspun, D. R., \& Adriaanse, H. P. (1996). Educational needs of stroke survivors and their family members, as perceived by themselves and by health

\section{Maloney \& Weiss}


professionals. Patient Education and Counseling, 28(3), 265-276.

Wade, J., Pletsch, P. K., Morgan, S. W., \& Menting, S. A. (2000). Hysterectomy: What do women need and want to know? Journal of Obstetric, Gynecologic, and Neonatal Nursing, 29(1), 33-42.

Walker, C., Hogstel, M. O., \& Curry, L. C. (2007). Hospital discharge of older adults. American Journal of Nursing, 107(6), 60-70.

Weiss, M., Johnson, N., Malin, S., Lang, C., Sherburne, E., \& Jerofke, T. (in press). Predictors and outcomes of readiness for hospital discharge in parents of hospitalized children. Journal of Pediatric Nursing.

Weiss, M. E., \& Piacentine, L. B. (2006). Psychometric properties of the Readiness for Hospital Discharge Scale. Journal of Nursing Measurement, 14(3), 163-180.

Weiss, M., Piacentine, L. B., Lokken, L., Ancona, J., Archer, J., Gresser, S., et al. (2007). Perceived readiness for hospital discharge in adult medical-surgical patients. Clinical Nurse Specialist, 21(1), 31-42. 


\section{Appendix}

Table 1

Characteristics of the Study Sample

\begin{tabular}{|c|c|c|}
\hline & \multicolumn{2}{|c|}{ Adult $(n=115)$} \\
\hline & No. & $\%$ \\
\hline \multicolumn{3}{|l|}{ Age } \\
\hline $18-44$ & 38 & 33.0 \\
\hline $45-54$ & 22 & 19.1 \\
\hline $55-64$ & 28 & 24.3 \\
\hline $65-100$ & 27 & 23.5 \\
\hline \multicolumn{3}{|l|}{ Gender } \\
\hline Female & 64 & 55.7 \\
\hline Male & 51 & 44.3 \\
\hline \multicolumn{3}{|l|}{ Race } \\
\hline White & 72 & 63.7 \\
\hline Nonwhite & 41 & 36.3 \\
\hline Black & 38 & 33.6 \\
\hline Hispanic & 1 & 0.9 \\
\hline Asian & 2 & 1.8 \\
\hline \multicolumn{3}{|l|}{ Education } \\
\hline Less than high school & 11 & 9.8 \\
\hline High school & 36 & 31.9 \\
\hline Partial college & 28 & 24.8 \\
\hline College and some graduate education & 38 & 33.6 \\
\hline Living arrangement-lives alone & 21 & 18.3 \\
\hline \multicolumn{3}{|l|}{ Hospitalization factors } \\
\hline Previous admission & 105 & 92.1 \\
\hline Planned admission & 55 & 49.1 \\
\hline \multicolumn{3}{|l|}{ Type of admission } \\
\hline Medical & 62 & 54.0 \\
\hline Surgical & 53 & 46.0 \\
\hline \multicolumn{3}{|l|}{ Medical diagnoses } \\
\hline Cardiac & 60 & 52.2 \\
\hline Pulmonary & 28 & 24.3 \\
\hline Diabetic & 21 & 18.4 \\
\hline \multicolumn{3}{|l|}{ Length of stay } \\
\hline 1-2 days & 34 & 30.6 \\
\hline 3-4 days & 38 & 34.2 \\
\hline 5-14 days & 39 & 35.1 \\
\hline
\end{tabular}

Note: Some categories do not total $n=115$ due to missing data. 
Table 2

Informational Content Needed and Received by Patient Characteristics and Hospitalization Factors

\begin{tabular}{|c|c|c|c|c|c|c|c|c|}
\hline \multirow{3}{*}{\begin{tabular}{|l|}
$\begin{array}{l}\text { Independent } \\
\text { Variables }\end{array}$ \\
$n=115$ \\
ANOVA results \\
\end{tabular}} & \multicolumn{8}{|c|}{ Dependent Variables } \\
\hline & \multicolumn{4}{|c|}{ QDTS Content Needed } & \multicolumn{4}{|c|}{ QDTS Content Received } \\
\hline & $M$ & $S D$ & $d f ; F$ & $p$ & $M$ & $S D$ & $d f ; F$ & $p$ \\
\hline Age & 26.2 & 15.6 & $\begin{array}{c}3,111 \\
0.47\end{array}$ & .71 & 37.5 & 15.52 & $\begin{array}{c}3,111 \\
0.18\end{array}$ & .91 \\
\hline Education & 26.2 & 15.3 & $\begin{array}{c}2,110 ; \\
1.70\end{array}$ & .19 & 37.5 & 15.41 & $\begin{array}{c}2,110 \\
1.00\end{array}$ & .37 \\
\hline Length of stay & 26.2 & 15.8 & $\begin{array}{c}2,110 \\
0.05\end{array}$ & .95 & 37.7 & 15.6 & $\begin{array}{c}2,110 \\
0.59\end{array}$ & .56 \\
\hline$t$-test results & $M$ & $S D$ & $t$ & $p$ & $M$ & $S D$ & $t$ & $p$ \\
\hline Gender & & & 0.82 & .42 & & & 1.73 & .09 \\
\hline Male & 27.6 & 16.1 & & & 40.3 & 15.0 & & \\
\hline Female & 25.2 & 15.3 & & & 35.3 & 15.8 & & \\
\hline Race & & & 3.10 & $.00^{* \star}$ & & & 1.25 & .21 \\
\hline Nonwhite & 32.1 & 14.9 & & & 40.1 & 14.1 & & \\
\hline White & 22.9 & 15.4 & & & 36.3 & 16.4 & & \\
\hline Living alone & & & -1.80 & .08 & & & -0.54 & .60 \\
\hline Yes & 31.7 & 15.0 & & & 39.2 & 13.6 & & \\
\hline No & 25.0 & 15.0 & & & 37.2 & 16.0 & & \\
\hline Prior admission & & & -0.20 & .84 & & & 2.20 & $.04^{*}$ \\
\hline Yes & 26.1 & 15.9 & & & 37.9 & 16.0 & & \\
\hline No & 27.2 & 13.7 & & & 32.0 & 6.6 & & \\
\hline Planned admission & & & -1.94 & .06 & & & -1.34 & .18 \\
\hline Yes & 28.7 & 16.2 & & & 39.3 & 14.9 & & \\
\hline No & 23.1 & 14.4 & & & 35.3 & 16.1 & & \\
\hline Type of admission & & & 0.73 & .47 & & & 0.80 & .43 \\
\hline Medical & 27.2 & 16.2 & & & 38.6 & 15.7 & & \\
\hline Surgical & 25.1 & 15.1 & & & 36.3 & 15.3 & & \\
\hline Cardiac diagnosis & & & -0.73 & .47 & & & -2.45 & $.02^{*}$ \\
\hline Yes & 27.2 & 16.1 & & & 40.9 & 15.7 & & \\
\hline No & 25.1 & 15.2 & & & 33.9 & 14.7 & & \\
\hline Pulmonary diagnosis & & & -0.47 & .64 & & & -1.04 & .30 \\
\hline Yes & 27.4 & 14.0 & & & 40.2 & 14.7 & & \\
\hline No & 25.8 & 16.2 & & & 36.7 & 15.8 & & \\
\hline Diabetic diagnosis & & & -1.01 & .31 & & & 1.08 & .28 \\
\hline Yes & 29.5 & 16.9 & & & 34.3 & 16.6 & & \\
\hline No & 25.7 & 15.3 & & & 38.3 & 15.3 & & \\
\hline
\end{tabular}

Note: QDTS = Quality of Discharge Teaching Scale.

${ }^{*} p<.05 .{ }^{* *} p<.01$. 